\title{
EMPREENDEDORISMO E INCENTIVOS GOVERNAMENTAIS PARA A SOBREVIVÊNCIA DE EMPRESAS NO PERÍODO DA PANDEMIA DO CORONAVÍRUS
}

\author{
ENTREPRENEURSHIP AND GOVERNMENT INCENTIVES FOR THE SURVIVAL OF COMPANIES \\ IN THE CORONAVIRUS PANDEMIC PERIOD
}

Recebido em 23.04.2021 Aprovado em 17.05.2021

Avaliado pelo sistema double blind review

DOI: https://doi.org/10.32888/cge.v9i1.49769

\author{
Jeferson Enrique dos Santos \\ jefersonhs93@gmail.com \\ Universidade Estadual do Paraná/Campus de Paranavaí - Paranavaí/Paraná, Brasil \\ https://orcid.org/0000-0002-6695-8364
}

\section{Edi Carlos de Oliveira}

edicarlosdeoliveira@hotmail.com

Universidade Estadual do Paraná/Campus de Paranavaí - Paranavaí/Paraná, Brasil

https://orcid.org/0000-0002-6316-6142

\section{Resumo}

O objetivo dessa pesquisa foi identificar quais incentivos governamentais foram disponibilizados aos empreendedores para contribuir com a manutenção de suas empresas no período de enfrentamento do Coronavírus. Para apoiar as análises, realizou-se uma pesquisa qualitativa, com abordagem descritiva, com 20 empreendedores de Santo Antônio do Caiuá, município localizado no noroeste do Estado do Paraná. As entrevistas semiestruturadas ocorreram de forma pessoal, respeitando as medidas de proteção diante da pandemia do Coronavírus. Os resultados apontaram que boa parte dos empreendedores perceberam que as medidas oferecidas aos empreendedores foram importantes para o estabelecimento de estratégias de sobrevivência de suas empresas no mercado.

Palavras-chave: Empreendedorismo. Incentivos Governamentais. Pandemia. Coronavírus.

\begin{abstract}
The objective of this research was to identify which government incentives were made available to entrepreneurs to contribute to the maintenance of their companies in the period of confrontation with the Coronavirus. To support the analyzes, a qualitative research was carried out, with a descriptive approach, with 20 entrepreneurs from Santo Antônio do Caiuá, a municipality located in the northwest of the State of Paraná. The semi-structured interviews took place in a personal way, respecting the protection measures in the face of the Coronavirus pandemic. The results showed that a good part of the entrepreneurs realized that the measures offered to the entrepreneurs were important for the establishment of survival strategies of their companies in the market.
\end{abstract}

Keywords: Entrepreneurship. Government Incentives. Pandemic. Coronavírus. 


\section{Introdução}

A pandemia de Covid-19, causada pelo vírus SARS-COV-2 ou Novo Coronavírus, vem produzindo repercussões sem precedentes, além de impactos socioeconômicos, demonstrando a necessidade de ações para contenção da mobilidade social, como isolamento e quarentena; porém, essas estratégias também contribuíram para elevar o número de desempregados no Brasil e no mundo, com altas taxas de empresas de segmentos diversos fechando suas portas temporariamente ou até chegando ao ponto de solicitar pedido de falência (OLIVEIRA, 2020).

Nesse contexto, o empreendedorismo surge como maneira de ocupar a lacuna deixada pela perca de empregos formais e pelo fechamento de empresas, tendo em vista que empreender por necessidade se caracteriza como uma realidade, na qual os empreendedores iniciam seus empreendimentos de maneira autônoma por não possuírem opções para trabalho e se veem diante da abertura de um negócio, a fim de gerar renda para manter suas famílias (MOREIRA, 2010).

No cenário contemporâneo, é de significativa a importância o desenvolvimento e implementação de ações governamentais em favor do empreendedor, que sofre com alta taxa de desemprego e riscos de quedas de pequenas e grandes empresas. Segundo o jornal El País (2020) é clara a dificuldade das empresas em se manterem sólidas perante a pandemia, pois a doença agregou dificuldades financeiras claras ao empreendedor e um colapso na economia dos países. Assim, não somente o empreendedor sofre essa turbulência no mercado, mas também o trabalhador, que sobrevive como a classe trabalhista mais baixa e tende a sofrer ainda mais com as consequências da pandemia.

Ressaltando como a pandemia afeta o empreendedor no mercado, deve haver o reconhecimento, por meio dos órgãos governamentais, em relação à importância desses indivíduos que implementam suas empresas e contribuem para com o desenvolvimento econômico do país (SCHUMPETER, 1982), pois são os empreendedores que energizam o mercado gerando empregos e são eles que giram a economia produtiva do país e fomentam a economia local (SEBRAE, 2007).

Segundo dados da pesquisa Global Entrepreneurship Monitor - GEM (2018) há um número relevante de pequenos empreendedores e que cresce rapidamente no mercado atual, ressaltando a grande importância desses altos números para o desenvolvimento do país. Por meio dos dados de 2002 a 2014, da referida pesquisa, o país obteve ganhos de até $14 \%$ de novos empreendedores no mercado, estimando um número de 48 milhões de empreendedores no total (GEM, 2014).

A partir desses dados, apresenta-se o objetivo dessa pesquisa, que consistiu em identificar quais incentivos governamentais foram disponibilizados aos empreendedores para contribuir com a manutenção de suas empresas no período de enfrentamento do Coronavírus. Assim, espera-se apresentar as relações dessa temática com o empreendedorismo e com os efeitos socioeconômicos causados pela Covid-19.

Em se tratando da estrutura de apresentação dos resultados dessa pesquisa, na sequência, evidencia-se a fundamentação teórica, que abarca teorias relacionadas ao tema e ao problema de pesquisa; seguida pelos procedimentos metodológicos, apresentação e análise dos resultados, considerações finais e as referências bibliográficas que foram utilizadas e encontram-se descritas ao longo desse artigo.

\section{Fundamentação teórica}

Essa seção tem por objetivo demonstrar abordagens teóricas que são apresentadas e utilizadas como forma de sustentar as discussões vinculadas ao objetivo da pesquisa. Assim, não se buscou esgotar teoricamente as discussões 
sobre as temáticas abordadas, mas simplesmente fundamentar conceitos e percepções teóricas de autores que discutem a temática em questão, sendo eles: Empreendedorismo; Estratégias e ações empreendedoras; Consequências de uma pandemia no âmbito das empresas; e, Incentivos governamentais disponibilizados às empresas para o enfrentamento da pandemia.

\section{Empreendedorismo}

O empreendedorismo pode ser compreendido como um caminho de investimentos em novos negócios, no qual o empreendedor observa e estuda nichos de mercado onde o empreendimento se desenvolve, bem como sua natureza, criação, desenvolvimento e a relação entre empreender e empreendedorismo (DOLABELA, 1999).

Dolabela (1999) descreve que o empreendedorismo consiste em incorporar novos caminhos na comunidade, favorecendo a implantação do conhecimento e a superação de obstáculos, levando a sociedade à introdução de um novo conteúdo e cooperação. Na visão de Schumpeter (1982), o empreendedorismo pode ser totalmente associado com inovação, de modo que o empreendedor tenha em suas mãos o poder de construir e inovar totalmente a economia existente, descartando tendências antigas por meio de novas ideias de inovação, além da superioridade de velhas tecnologias ou negócios, atuando e contribuindo totalmente para com a economia de um país.

Observa-se, também, a dificuldade de caracterização do empreendedorismo por meio de empreendedores que não possuem uma maneira sólida de empreender; assim, nota-se o modelo de empreendimento no tocante à maneira peculiar de pensar do empreendedor, levando-se em consideração suas características e ações, que interferem diretamente em suas ações empreendedoras no mercado (DOLABELA, 1999).

De acordo com Global Entrepreneurship Monitor (2020), o Brasil deveria atingir, no ano de 2020, o maior patamar de empreendedores iniciais dos últimos 20 anos, com aproximadamente $25 \%$ da população adulta envolvida na abertura de um novo negócio ou com um negócio com até 3,5 anos de atividade. O recorde estimado é verificado de acordo com a análise da série histórica da pesquisa GEM, que aponta aumento do empreendedorismo. Em complemento, estima-se que a atual crise (sem precedentes), causada pela pandemia do novo Coronavírus, deve impulsionar o número de pessoas que podem buscar o empreendedorismo como uma alternativa de renda, tendose em vista dificuldades tanto na busca quanto na manutenção de empregos.

\section{Estratégias e ações empreendedoras}

Para se pensar em estratégia, deve-se voltar ao conceito de planejamento estratégico, que é definido por Kotler (1992) como um processo no qual se analisa as mudanças atuais e futuras do mercado e as associam em manter os recursos da empresa preparados para eventuais mudanças no ambiente futuro, de modo que as empresas devem se preparar para sobreviver a qualquer tipo de evento no ambiente, proveniente tanto do ambiente interno quanto do ambiente externo.

Segundo estudos de Mintzberg e Quinn (2001) estratégia consiste em gerir as metas, políticas e organização, de modo que a estratégia organizada tende a solucionar perdas, tornando a tomada de decisões mais facilitada e rápida. Para esses autores, os empreendedores mais preparados e as organizações estratégicas tendem a se estabilizar mais facilmente em virtude desses possíveis eventos, garantindo a manutenção de suas atividades no mercado.

Verifica-se, portanto, o planejamento estratégico como o maior processo de uma organização, proporcionado por uma visão ampla e de longo prazo, que é tratada como sendo de vital importância pelos órgãos mais relativos da empresa, que interferem em eventos futuros no cotidiano dessas organizações (MOT'TA, 1992). 
Para Chiavenato e Sapiro (2003), planejamento estratégico não deve ser classificado como uma ação de longo prazo, mas sim, de curto e médio prazos, visto que deve ser elaborada e implementada por meio de processos que levem em consideração os objetivos organizacionais. Esses autores definem que a empresa deve se posicionar, observar e analisar seu(s) ambiente(s), definindo suas estratégias atuais e observando as possíveis ameaças e oportunidades do mercado [sendo essas provenientes do ambiente externo].

No que diz respeito às dificuldades enfrentadas pelas empresas e seus empreendedores desde o início do ano de 2020, em função da pandemia causada pelo Covid-19, que está afetando empresas de diversos setores e/ou segmentos do mercado, muitas empresas precisaram até suspender suas atividades, respeitando decretos municipais e estaduais.

Conforme Munhoz (2020), as mudanças no ambiente e no cenário de marketing forçaram as organizações a desenvolver uma agilidade estratégica durante pandemia. Assim, enquanto os estrategistas defendem a agilidade na elaboração de estratégias, a velocidade da disseminação do Covid-19 exige das organizações uma agilidade empreendedora com maior flexibilidade, sempre pensando em novas estratégias para atuação nesse momento extremamente dinâmico e complexo, o que justifica ainda mais a prática e implementação de ações estratégicas por parte das empresas para o enfrentamento da pandemia em questão.

\section{Consequências de uma pandemia no âmbito das empresas}

São várias as consequências de uma pandemia no segmento organizacional. Segundo dados da Fundação Instituto de Administração - FIA (2020), 88\% dos empreendedores viram seu negócio desabar durante a pandemia, entre eles se destacam os pequenos e microempreendedores. Segundo relatos de empreendedores, as perdas chegaram a mais de $75 \%$ e muitos fecharam suas portas. Observa-se, também, segundo dados do Instituto Brasileiro de Geografia e Estatística - IBGE (2020), que das empresas que ainda estavam em funcionamento antes da pandemia, $70 \%$ sentiram os efeitos (direta e/ou indiretamente), na maioria aquelas que funcionavam em total proximidade com o cliente, tendo assim que mudar totalmente suas práticas para não fecharem suas portas, sendo que algumas das medidas adotadas pelas empresas estão apresentadas no gráfico 1.

Gráfico 1 - Medidas adotas nas empresas em relação aos impactos da Covid-19

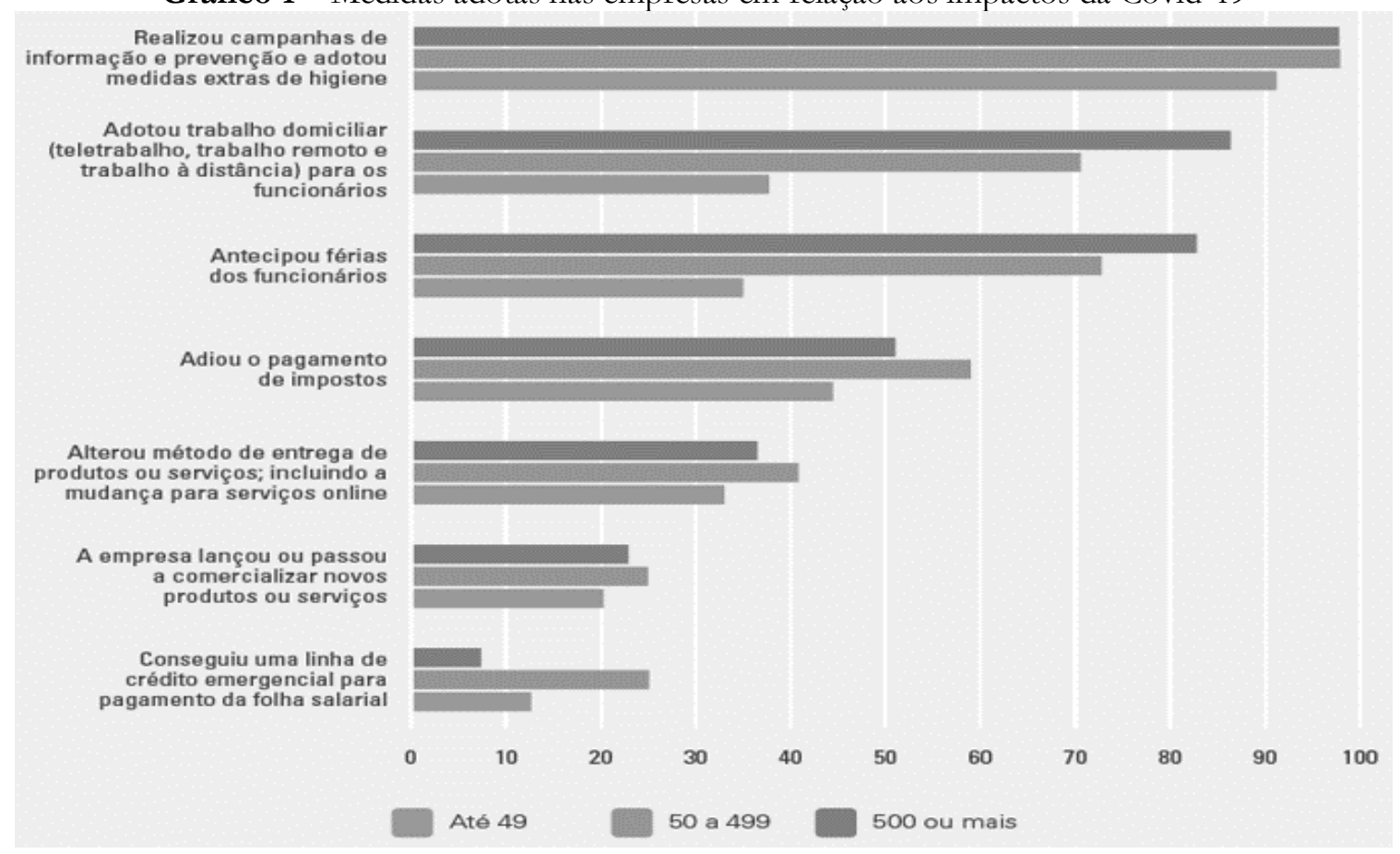

Fonte: IBGE (2020). 
Por meio dos dados expressados por meio do gráfico 1, percebe-se que a quantidade de funcionários (até 49; de 50 a 499; 500 ou mais) não interferiu nas estratégias adotadas pelas empresas durante a pandemia. Dessa forma, as estratégias adotadas em menor e maior escala são, respectivamente: busca de linha de crédito emergencial para pagamento da folha salarial; ampliação no portfólio de produtos comercializados; alteração no método de entrega de produtos/serviços, incluindo serviços online; adiamento do pagamento de impostos; antecipação das férias dos funcionários; adoção de trabalho domiciliar (home-office) para os funcionários; e, realização de campanhas de informação e prevenção, sempre adotando medidas de higiene para contenção do vírus.

Logo nos primeiros meses da pandemia causada pelo novo Coronavírus, pelo menos $600 \mathrm{mil} \mathrm{micro/pequenas}$ empresas fecharam as portas e nove milhões de funcionários foram demitidos em razão dos efeitos econômicos decorrentes da pandemia do novo Coronavírus. É o que mostra o levantamento feito pelo Serviço Brasileiro de Apoio às Micro e Pequenas Empresas - SEBRAE, que destaca que 30\% dos empreendedores tiveram que buscar empréstimos para manter seus negócios, mas o resultado não tem sido positivo, pois $29,5 \%$ destes empreendedores ainda aguardam uma resposta das instituições financeiras e 59,2\% simplesmente tiveram seus pedidos negados.

Outro dado relevante é apresentado pela FIA (2020), que destacou que quando analisado os nichos de serviços e produtos, verificou-se a queda de lucros por parte das empresas, por exemplo: empresas aéreas e de transporte de passageiros, que tiveram que mudar totalmente seus processos, além dos restaurantes e alguns centros comerciais que fecharam totalmente suas portas por alguns períodos durante o ano. Essas e outras evidências da realidade das empresas atuantes no mercado no contexto da pandemia confirmam que o impacto da crise atingiu todos os setores da economia, mas foi pior para o setor de serviços, que é o maior gerador de empregos do país e foi mais profundo também entre as pequenas empresas (IBGE, 2020).

\section{Incentivos governamentais disponibilizados às empresas para o enfrentamento da pandemia}

Prevendo um estado de calamidade no país, o governo adotou medidas provisórias para assim tentar reduzir os impactos e efeitos da pandemia do Coronavírus, observando-se uma possível baixa na economia do país e também relacionada ao desemprego (SEBRAE, 2020).

Dentre as medidas estabelecidas pelo governo para o enfrentamento da pandemia do coronavírus estão: o banco de horas, alterações em relação às férias e pagamento do Fundo de Garantia por Tempo de Serviço - FGTS, mudanças em relação à compensação da jornada laboral (PARMAIS, 2021), além de medidas que foram elaboradas no âmbito dos estados e municípios.

O governo instituiu o Programa Nacional de Apoio às Microempresas e Empresas de Pequeno Porte PRONAMPE, inovando em apoio aos pequenos negócios que hoje são uma das maiores rendas do país. No entanto, para a aquisição do benefício foi necessário que a empresa estivesse com pelo menos um ano em funcionamento, objetivando assim os créditos a serem usados para o que fosse mais vantajoso (PARMAIS, 2021).

O Programa Emergencial de Suporte e Empregos - PESE, do Banco Nacional de Desenvolvimento Econômico e Social - BNDES, foi criado no mês de agosto do ano de 2020, sendo que em sua primeira fase conseguiu aprovação e apoio de várias micro e grandes empresas, sendo que toda essa ação beneficiou mais de 1,9 milhões de empregados em todo o território nacional. O PESE se destinou ao pagamento de verbas trabalhistas e também teve como objetivo operações de crédito para pagamento de folha salarial (PARMAIS, 2021).

Além disso, foi também anunciada a medida provisória 944, que estabeleceu uma linha de crédito direcionada às empresas com renda anual entre 360 mil e 10 milhões, com valor estimado em 34 bilhões de reais, com foco 
principal na colaboração às empresas, para que as mesmas pudessem honrar os pagamentos dos salários de seus funcionários (PARMAIS, 2021).

Observou-se, também, uma outra medida adotada pelo governo, que foi a divulgação de mais uma linha de crédito destinada a financiar a folha salarial das empresas, sendo este crédito especial com valor de aproximadamente 40 bilhões, que foi disponibilizado às empresas que possuíam renda estimada entre 360 mil e 10 bilhões de reais sem sua receita, com uma carência de até seis meses após a operação para começar a pagar (PARMAIS, 2021).

O governo também entrou em ação e editou a medida provisória 936/20, que possibilitou às empresas a redução de carga horária laboral dos trabalhadores, bem como a diluição do salário recebido. Desse modo, o governo ficou à disposição para o pagamento dos trabalhadores em caso de redução ou suspenção de contrato de trabalho (PARMAIS, 2021).

Segundo Parmais (2021) o Conselho Monetário Nacional - CMN entrou com processo em que autorizou as pessoas físicas e empresas de pequeno porte a terem a chance de renegociar suas dívidas, solicitando adiamento do prazo em até 60 dias depois do vencimento, sendo que somente as dívidas como cartão de crédito e dívidas com cheques especiais não poderiam ter o direito ao benefício.

Em relação aos incentivos fiscais, o governo apostou em ações mais objetivas que pudessem propiciar a permanência das empresas no mercado, com o objetivo principal de ajudar as empresas a se manterem no mercado durante a crise instaurada pela pandemia. Assim, no início do ano de 2021, o governo federal implementou mais duas medidas voltadas à manutenção dos empregos e ao pagamento dos salários dos trabalhadores, na tentativa de reduzir os impactos e os efeitos econômicos derivados da pandemia. Trata-se do adiamento de 3 meses, por parte das empresas, para o pagamento do imposto Simples Nacional e a liberação de crédito por meio do Programa de Geração de Renda - PROGER, destinados a melhorar o capital de giro das empresas (MINISTÉRIO DA ECONOMIA, 2021).

Além dessas medidas adotadas no início do ano de 2021, o governo federal também anunciou o pagamento antecipado do $13^{\circ}$ salário dos pensionistas e aposentados, bem como a liberação de verbas adicionais ao Programa Bolsa Familia, incrementando a circulação de mais dinheiro no mercado (MINISTÉRIO DA ECONOMIA, 2021) na tentativa de contribuir com os empreendedores no que diz respeito à manutenção de suas empresas no período de enfrentamento do Coronavírus.

Outro incentivo que se mostrou indiretamente favorável às empresas foi o Auxílio emergencial, tendo em vista que ao beneficiar o trabalhador que não estava exercendo atividades laborais, esse recurso acabou sendo destinado ao mercado, na aquisição de produtos de primeira necessidade, pelo trabalhador, o que contribuiu para que as empresas continuassem movimentando a economia local e garantindo sua sobrevivência no mercado em tempos bastante incertos e sombrios.

\section{Procedimentos metodológicos}

Essa seção tem por objetivo delinear o percurso metodológico utilizado para o desenvolvimento dessa pesquisa, demonstrando as etapas, métodos e procedimentos de coleta e análise dos dados.

Na visão de Tartuce (2006), método é o caminho para se atingir um objetivo, por meio de um banco de informações obtidas sobre um assunto, que é definido um caminho para o fim e que dados são obtidos e esclarecidos em debates com diferentes teorias, se tornando informações preciosas para a conclusão de tal assunto.

Quanto ao método de pesquisa utilizada, configura-se como uma pesquisa qualitativa, que não requer o uso de análises estatísticas, na qual o pesquisador adere a utilização de coleta de dados para análise e obtenção de resultados, de modo a verificar a realidade e relação do objeto prescrito (GIL, 2008). 
Quanto ao objetivo, a pesquisa foi desenvolvida por meio da discussão de um tema, com foco no objetivo geral de identificar quais incentivos governamentais foram disponibilizados aos empreendedores para contribuir com a manutenção de suas empresas no período de enfrentamento do Coronavírus. Buscou-se identificar as medidas desenvolvidas pelo Governo Federal e pelos demais entes da Federação para atenuar o impacto socioeconômico causado aos empreendedores e às suas respectivas empresas. Assim, para melhor compreensão da temática em questão, foi necessária a abordagem dos empreendedores diante deste cenário atual.

Realizou-se, então, uma pesquisa com 20 empreendedores do município de Santo Antônio do Caiuá, localizado na região Noroeste do Estado do Paraná, utilizando-se do método qualitativo (GIL, 2008) e descritivo (VERGARA, 2004), com a realização de entrevistas semiestruturadas (BAUER; GASKELL, 2007) com os empreendedores no mês de outubro do ano de 2020 .

As entrevistas semiestruturadas ocorreram de forma pessoal, em encontros marcados diretamente com os empreendedores, sempre respeitando os limites e precauções diante da pandemia do Covid-19. Foram entrevistados um total de 20 empreendedores (dezoito homens e duas mulheres).

$\mathrm{Na}$ etapa de coleta de dados desta pesquisa, utilizou-se também de dados secundários (RICHARDSON, 1999), que são o conjunto de informações que já foram coletadas por outras pessoas durante um processo de pesquisa diferente, sendo que a coleta de dados se deu por meio de websites governamentais e de referenciais teóricos de credibilidade, corretamente referenciadas no presente artigo.

Por meio da metodologia utilizada, foi possível analisar os resultados obtidos e obter informações relevantes sobre os empreendedores do município de Santo Antônio do Caiuá - PR e abordar com mais clareza as ações governamentais que foram disponibilizadas aos empreendedores no enfrentamento da pandemia do coronavírus, bem como os programas que, de fato, beneficiaram esses empreendedores, tornando o objetivo da pesquisa mais específico.

A análise de dados foi realizada por meio da apreciação de categorias de análise, sustentada pela técnica de análise de conteúdo, que se caracteriza como uma técnica de investigação que tem por finalidade a descrição objetiva, sistemática e qualitativa do conteúdo manifesto da comunicação (BARDIN, 1997).

Conforme Bardin (1997), a análise de conteúdo é um conjunto de técnicas de análise das comunicações, que emprega procedimentos sistemáticos e objetivos de descrição do conteúdo das mensagens, que contribui para a sistematização e interpretação dos dados, permitindo a confrontação desses com a literatura que dispõe a temática em investigação.

Por fim, pode-se dizer que a metodologia utilizada ao longo da realização dessa pesquisa contribuiu para o alcance do objetivo proposto, sendo que os resultados estão apresentados na próxima seção desse artigo.

\section{Apresentação e análise dos resultados}

Essa pesquisa foi realizada no município de Santo Antônio do Caiuá - PR, um município localizado na região Noroeste do Estado do Paraná; sendo que os dados obtidos foram provenientes de entrevistas semiestruturadas com um total de 20 empreendedores que atuam nos segmentos de indústria, comércio e prestação de serviços, sendo esses dezoito homens e duas mulheres.

Primeiramente, com a coleta básica de dados, buscou-se identificar o gênero e a idade desses(as) empreendedores(as), no qual os resultados apontaram um dado muito importante em relação ao desenvolvimento, observando-se jovens que já possuem seu próprio negócio no mercado.

O quadro 1, a seguir, apresenta os dados relacionados ao perfil empreendedor: gênero, idade, escolaridade, segmento de atuação dos empreendedores e o tempo das empresas no mercado. 


\begin{tabular}{|c|c|c|c|c|}
\hline Gênero & Idade & Escolaridade & Segmento de atuação & $\begin{array}{l}\text { Tempo da empresa } \\
\text { no mercado }\end{array}$ \\
\hline Feminino & 43 anos & Ensino médio & Comércio & 7 anos \\
\hline Feminino & 29 anos & Ensino Superior & Comércio & 3 anos \\
\hline Masculino & 27 anos & Ensino médio & Serviços & 2 anos \\
\hline Masculino & 29 anos & Ensino Superior & Comércio & 1 ano \\
\hline Masculino & 29 anos & Ensino médio & Comércio & 3 anos \\
\hline Masculino & 30 anos & Ensino médio & Comércio & 4 anos \\
\hline Masculino & 31 anos & Ensino Superior & Serviços & 2 anos \\
\hline Masculino & 36 anos & Ensino Superior & Comércio & 8 anos \\
\hline Masculino & 38 anos & Ensino Superior & Comércio & 2 anos \\
\hline Masculino & 38 anos & Ensino médio & Serviços & 9 anos \\
\hline Masculino & 40 anos & Ensino médio & Comércio & 10 anos \\
\hline Masculino & 44 anos & Ensino médio & Serviços & 4 anos \\
\hline Masculino & 48 anos & Ensino médio & Comércio & 9 anos \\
\hline Masculino & 49 anos & Ensino médio & Comércio & 8 anos \\
\hline Masculino & 53 anos & Ensino médio & Comércio & 11 anos \\
\hline Masculino & 55 anos & Ensino Fundamental & Comércio & 23 anos \\
\hline Masculino & 58 anos & Ensino médio & Indústria & 16 anos \\
\hline Masculino & 61 anos & Ensino Fundamental & Comércio & 32 anos \\
\hline Masculino & 63 anos & Ensino médio & Comércio & 25 anos \\
\hline Masculino & 66 anos & Ensino Fundamental & Indústria & 35 anos \\
\hline
\end{tabular}

Quadro 1: Perfil e atuação dos empreendedores

Fonte: Dados da pesquisa.

Quanto ao perfil dos empreendedores, percebeu-se que a maioria possui apenas ensino médio (12 empreendedores), 5 empreendedores possuem ensino superior e 3 empreendedores possuem ensino fundamental. O segmento de atuação prevalecente é o comércio (14 empreendimentos), seguido pelo segmento de prestação de serviços (4 estabelecimentos) e 2 empreendimentos industriais.

Em se tratando do tempo de atuação no mercado, em média as empresas atuam há 10 anos no mercado, com empresas que atuam há apenas um ano e outras há 35 anos. Ao se observar esses dados com cortes, entre 1 e 2 anos de atuação são 4 empresas; entre 3 e 5 anos de atuação são 4 empresas; entre 6 a 10 anos de atuação são 6 empresas; entre 11 e 20 anos de atuação são 2 empresas; e, com mais de 20 anos de atuação são 4 empresas, sendo que duas delas atuam no mercado há mais de 30 anos.

Observou-se, também, que dentre os entrevistados 50\% deles não obtiveram ou não buscaram um auxílio do governo durante o enfrentamento da pandemia, mas obtiveram ou sentiram o impacto da pandemia em seus negócios. Os outros 50\% buscaram os incentivos governamentais para garantir o pagamento dos funcionários, sendo que desses, $20 \%$ relataram que o auxílio não foi o suficiente para restituir suas perdas, já os outros entrevistados relataram que o auxílio evitou um possível fim de seus negócios.

Dentre os benefícios buscados pelos empreendedores, pode-se listar: 7 empreendedores adotaram o banco de horas com diluição do salário dos trabalhadores, como estratégia para a manutenção dos empregos; 3 empreendedores buscaram auxílio junto ao Programa Emergencial de Suporte e Empregos, do BNDES, que fomentou ajuda e serviu para o pagamento de verbas trabalhistas (em um caso) e para pagamento de folha salarial (em dois casos), sendo que esse crédito tem uma carência de 6 meses - o que contribui para que o empreendedor consiga controlar sua instabilidade no mercado; 8 empreendedores solicitaram valores junto aos bancos, por meio de políticas públicas como o Programa Nacional de Apoio às Microempresas e Empresas de Pequeno Porte (PRONAMPE); porém, apenas 2 empreendedores tiveram suas solicitações de linha de crédito deferidas pela instituição financeira e os outros 6 empreendedores não foram beneficiados pela justificativa de inadimplência em que se encontravam (mesmo essa inadimplência sendo em virtude pandemia do Coronavírus); 2 empreendedores foram beneficiados com o auxílio do Conselho Monetário Nacional, que autorizou a renegociação de dívidas, com adiamento do prazo em 60 dias depois do vencimento; 11 empreendedores conseguiram o adiamento de 3 meses 
para o pagamento do imposto Simples Nacional; e, 2 empreendedores foram beneficiados com a liberação de crédito por meio do PROGER, para a melhoria do capital de giro das empresas.

Do total de 20 empreendedores, um deles não tinha conhecimento dos benefícios implementados pelo governo para auxílio ao enfrentamento da pandemia do coronavírus; dois outros não buscaram auxílio, mas conheciam os programas oferecidos pelo governo; e, cabe o destaque de que nove empreendedores foram beneficiados em mais de um programa de auxílio oferecido pelo governo federal.

A partir da demonstração das medidas adotadas pelo Governo Federal para atenuar as consequências causadas pela pandemia do novo Coronavírus, especificamente para o enfrentamento da pandemia, percebeu-se que com a flexibilização de leis trabalhistas, como concessão de férias, banco de horas e flexibilização do pagamento do FGTS pelos empregadores, assim como a criação de Medidas Provisórias, como a MP 944, MP 936/20, e a criação do Programa Nacional de Apoio às Microempresas e Empresas de Pequeno Porte (PRONAMPE) e o Programa Emergencial de Suporte a Empregos - PESE do BNDES, a prorrogação do pagamento de Impostos Federais dos Micro Empreendedores Individuais (MEI's), e a criação do Auxilio Emergencial, possibilitou a geração de renda para pessoas que perderam seus empregos; aqueceu a economia com a liquidez de dinheiro no mercado, conforme apontado por Parmais (2020) e pelo Ministério da Economia (2021).

Além disso, segundo relatos apresentados pelos entrevistados, o benefício governamental que mais contribuiu para as empresas foi o auxílio emergencial, que mesmo não sendo um incentivo governamental "direto" para as empresas, fez com que os resultados se mostrassem de modo "indireto" bastante favoráveis aos empreendedores e às suas empresas. Como grande parte dos empreendedores entrevistados estão inseridos do segmento de comércio e prestação de serviços, o auxílio emergencial possibilitou aos clientes dos empreendedores a obtenção de renda, que possibilitou manter a economia local aquecida.

Mesmo com relatos positivos obtidos, a maioria dos entrevistados questionaram a ação do governo principalmente quando limitaram suas áreas e ações perante a ação do vírus, já que muitos tiveram suas portas fechadas, ocasionando o acúmulo de dívidas e dispensa de lucros. Desse modo, observando os dados e relatos obtidos na pesquisa, foi possível esclarecer o pouco conhecimento dos pequenos empreendedores em lugares remotos ou longe de grandes centros urbanos como capitas, além de observar a oscilação dos benefícios oferecidos pelo governo entre pequenos, médios e grandes empreendedores.

\section{Considerações finais}

Ao se findar esse processo de pesquisa científica e diante do que foi apresentado ao longo desse artigo, pôde-se perceber o quão valoroso foram os benefícios oferecidos às empresas e aos cidadãos para o enfrentamento da pandemia do coronavírus, independentemente do tipo do negócio e segmento de atuação no mercado. Dentre as discussões desse estudo foi ressaltada a finalidade dos incentivos governamentais implementados pelo Governo Federal e demais entes da Federação para atenuar os impactos socioeconômicos causados pelo vírus SARS-COV2 ou novo coronavírus.

A partir deste cenário caótico e preocupante, procurou-se compreender quais medidas o Governo Federal implementou para que empreendedores(as) pudessem manter suas empresas em atividade e quais dessas medidas favoreceram os 20 empreendedores(a) do município de Santo Antônio do Caiuá - PR, para que estes tivessem o mínimo de prejuízos possíveis.

Assim, constatou-se que as medidas que beneficiaram os empreendedores foram: o banco de horas com diluição do salário dos trabalhadores; auxílio financeiro para o pagamento de verbas trabalhistas e para pagamento de folha salarial; auxílio financeiro junto aos bancos, por meio do PRONAMPE; benefício do Conselho Monetário Nacional, que autorizou a renegociação de dívidas; benefício do adiamento de 3 meses para o pagamento do 
imposto Simples Nacional; e, a liberação de crédito por meio do PROGER, para a melhoria do capital de giro das empresas.

Constatou-se, também, que dos 20 empreendedores que participaram da pesquisa, um deles não tinha conhecimento dos benefícios implementados pelo governo para auxilio no enfrentamento à pandemia do coronavírus e dois deles não manifestaram interesse nos auxílios oferecidos; porém, evidenciou-se que nove empreendedores foram beneficiados em mais de um programa de auxílio oferecido pelo governo federal.

Nesse sentido, a percepção de grande parte dos empreendedores entrevistados foi de que as medidas adotadas e oferecidas aos empreendedores pelo governo foram importantes para o estabelecimento de estratégias de sobrevivência de suas empresas no mercado, pois uma parte significativa dos entrevistados não tinha um caixa de emergência (reserva financeira) para eventuais contingências, e que apesar da flexibilidade de leis trabalhistas e a facilitação de conceção de linha de crédito com juros reduzidos e com prazos de pagamento prorrogados, nem todos os empreendedores(as) entrevistados(as) conseguiram ter acesso ao crédito.

Deste modo, evidencia-se que o objetivo desta pesquisa foi alcançado, pois foi possível identificar as medidas governamentais implementadas com objetivo de amenizar os impactos da pandemia do coronavírus nas empresas desses empreendedores(as) de Santo Antônio do Caiuá - PR; além de ter fomentado uma discussão sobre a real eficácia que tais medidas tiveram para evitar maiores danos econômicos às empresas mencionadas.

Observou-se por meio dos achados da pesquisa, a importância dos empreendedores(as) e de suas empresas estarem sempre preparados para possíveis contingências (eventos inesperados) em seu segmento de atuação no mercado sendo essa uma das contribuições dessa pesquisa; e, que as ações e medidas governamentais implementadas causaram impactos tanto positivos quanto negativos, na tentativa de manter a economia aquecida.

Constatou-se que a presente pesquisa tem relevância, devido ao momento histórico vivido pela sociedade e também em função da escassa literatura publicada sobre os efeitos da pandemia causada pelo vírus SARS-COV-2 ou Novo Coronavírus em relação aos empreendedores, sobretudo em municípios menores. Assim, espera-se que essa pesquisa sirva como base para a realização de outras pesquisas relacionadas em outros municípios, em termos de comparação e referência para eventuais pesquisas futuras que abordem a temática em questão.

\section{Referências}

BARDIN, L. Análise de Conteúdo. Lisboa: Edições 70, 1997.

BAUER, M. W.; GASKELL, G. Pesquisa Qualitativa com Texto, Imagem e Som: Um manual prático. 6 ed. Petrópolis: Vozes, 2007.

CHIAVENATO, I.; SAPIRO, A. Planejamento Estratégico. Rio de Janeiro: Elsevier, 2003.

DOLABELA, F. Oficina do Empreendedor. São Paulo: Cultura Editores Associados, 1999.

EL PAIS- O desafio econômico de sobreviver à pandemia na América Latina. Cidade Do México / Bogotá / São Paulo / Buenos Aires. Disponível em: <https://brasil.elpais.com/ economia/2020-08-18/o-desafioeconomico-de-sobreviver-a-pandemia-na-america-latina.html > > Acesso em 21 set 2020.

FABRETTI, L. C. Contabilidade Tributária. 2 ed. São Paulo: Atlas, 2009.

FIA - Fundação Instituto de Administração. Coronavírus e o impacto nos negócios: como preparar sua empresa?, Disponível em: <https://www.fia.com.br/blog/coronavirus-e-o-impacto-nos-negocios/>. Acesso em 21 set 2020. 
GEM- Global Entrepreneurship Monitor. Empreendedorismo no Brasil. 2014 Disponível em: $<$ https://www.sebrae.com.br/Sebrae/Portal\%20Sebrae/Estudo\%20e\%Pesquisas/gem\%202014_relat\%CC3\%B3 rio\%20executivo.pdf>. Acesso em 16 mar 202Pesquisa0.

GEM - Global Entrepreneurship Monitor. 2018: Análise dos resultados por gênero. Disponível em: <https://www.sebrae.com.br/Sebrae/Portal $\% 20$ Sebrae/UFs/GO/Sebrae $\%$ 20de $\% 20$ A $\% 20 \mathrm{a} \% 20 \mathrm{Z} / \mathrm{GEM} \% 20$ $\% 20 \mathrm{An} \% \mathrm{C} 3 \%$ A 1 lise $\% 20$ por\%20g\%C3\%AAnero\% 202018\%20finalv1\%20(002).pdf> Acesso em 16 mar 2020.

GIL, A. C. Métodos e técnicas de pesquisa social. 6 ed. São Paulo: Atlas, 2008.

GOVERNO do Brasil. Governo cria novo programa de apoio às micro, pequenas e médias empresas. Disponível em: <https://www.gov.br/pt-br/noticias/financas-impostos-e-gestao-publica/2020/07/governocria-novo-programa-de-apoio-as-micro-pequenas-e-medias-empresas> Acesso em 21 set 2020.

IBGE - Instituto Brasileiro de Geografia e Estatística. Pandemia foi responsável pelo fechamento de 4 em cada 10 empresas com atividades encerradas. Disponível em: <https://agenciadenoticias.ibge.gov.br/agencianoticias/2012-agencia-de->, Acesso em 16 ago 2020.

KOTLER, P. Administração de Marketing: Análise, Planejamento, Implementação e Controle. 2 ed. São Paulo: Atlas, 1992.

MINISTÉRIO DA ECONOMIA. Empreendedorismo: Governo anuncia medidas de ajuda econômica para micro e pequenas empresas. Disponível em: <www.gov.br/pt-br/noticias/ financas-impostos-e-gestaopublica/2020/03/governo-anuncia-medidas-de-ajuda-economica-para-micro-e-pequenas-empresas $>$ Acesso em 25 fev 2021.

MINTZBERG, H.; QUINN, J. B. O Processo da Estratégia. 3. ed. Porto Alegre: Bookman, 2001.

MOREIRA, P. A. Contexto de empreendedorismo. Brasilia: Elsevier, 2010.

MOTTA. P. R. Dimensões Gerenciais do Planejamento à Gestão Estratégica. Caderno de Administração. Belo Horizonte. v. 1. 1992.

MUNHOZ, J. V. As mudanças no comportamento do consumidor durante e pós-coronavírus; Disponível em: <https://www.paripassu.com.br/blog/comportamento-consumidor-coronavirus/> Acesso em 26 ago 2020.

OLIVEIRA, J. 716.000 empresas fecharam as portas desde o início da pandemia no Brasil, segundo o IBGE. Disponível em: <https://brasil.elpais.com/brasil/2020-07-19/716000-empresas-fecharam-as-portasdesde-o-inicio-da-pandemia-no-brasil-segundo-o-ibge.html> Acesso em 26 ago 2020.

PARMAIS. Medidas decretadas pelo governo para empresas e trabalhadores durante a pandemia. Disponível em: <https://www.parmais.com.br/blog/medidas-decretadas-pelo-governo-para-empresas-etrabalhadores-durante-a-pandemia>. Acesso em: 25 fev 2021.

RICHARDSON, R. J. Pesquisa social: métodos e técnicas. São Paulo: Atlas, 1999.

SCHUMPETER, J. Teoria do desenvolvimento econômico. São Paulo: Abril Cultural, 1982.

SEBRAE. Disciplina de empreendedorismo. São Paulo: Manual do aluno, 2007.

SEBRAE. Brasil deve atingir marca histórica de empreendedorismo em 2020. Disponível em: $<$ https://www.agenciasebrae.com.br/sites/asn/uf/NA/brasil-deve-atingir-marca-historica-

deempreendedorismoem2020,d9c76d10f3e92710VgnVCM1000004c00210aRCRD\#: :text=Em\%202020\%2C\% 20o\%20Brasil $\% 20$ deve,3\%2C5\%20anos\%20de\%20atividade>. Acesso em 28 fev 2021.

TARTUCE, T. J. A. Métodos de pesquisa. Fortaleza: UNICE - Ensino Superior, 2006.

VERGARA, S. C. Projetos e relatórios de pesquisa em administração. 8 ed. São Paulo: Atlas, 2004. 